\title{
Efficacy of inhaled methoxyflurane for procedural analgesia in paediatric burns: a pillot study
}

\author{
MA Wellbeloved, ${ }^{1}$ (D) R Parkhurst, ${ }^{2}$ (D) KH Keeling ${ }^{3}$ \\ 'Department of Anaesthesiology, University of the Witwatersrand, South Africa \\ ${ }^{2}$ Department of Paediatric Surgery, University of the Witwatersrand, South Africa \\ ${ }^{3}$ Department of Paediatric Critical Care, University of the Witwatersrand, South Africa \\ Corresponding author, email: nutmeg.m@gmail.com
}

Background: Methoxyflurane (MF), a volatile anaesthetic agent is known for its analgesic properties in sub-anaesthetic concentrations. It has been used as an analgesic agent for short procedures in both adults and children in the prehospital setting and in the emergency department. We conducted a pilot study to investigate the use of MF for burn dressing changes in children. Methods: A prospective case series was conducted in the paediatric burns ward amongst children aged 4-9 years. During burns dressing changes MF was administered using a hand-held patient-controlled device. An investigator monitored vital signs together with pain scores, sedation levels and levels of satisfaction of staff.

Results: Twelve patients were enrolled for the study. The majority of the burn wounds were classified as partial-thickness wounds. Methoxyflurane was used as the sole agent for analgesia and sedation for the procedure. No major adverse events were noted. Analgesia and sedation levels were sufficient and appropriate respectively for the majority of the patients during the initial exposure of the wound and the application of the new dressing. However, during the scrubbing of the burn wound analgesia and sedation proved insufficient in four and seven of the patients respectively.

Conclusion: In our setting the use of MF for inpatient burn wound dressing changes may be insufficient as a sole agent in the paediatric patient. We suggest it may be used as an adjunct to current practice. Further, larger studies are required to delineate the appropriate role MF can play in the paediatric burns setting.

Keywords: paediatric burns, pain, sedation, analgesia, methoxyflurane

\section{Introduction}

Burn related injuries have caused a massive burden on the health care system worldwide, with more than 300000 burn cases estimated to have occurred annually amongst children under the age of 5 years. ' However, this is only an estimate as the precise number of cases is unknown. ${ }^{2,3}$ Data showed that the incidence of hospitalised paediatric burn patients is highest in Africa. ${ }^{2,4}$ In Sub-Saharan Africa, $83.6 \%$ of all burn injuries occurred in children between the ages $0-10.4,5$

Burn injuries can be extremely painful and often require multiple procedures and interventions throughout the child's admission, including repeated wound exposures and debridements. Procedural analgesia and sedation are of paramount importance to reduce pain and anxiety ensuring early and extensive debridement, when needed, which will allow for improved healing as well as preventing fear of future procedures when it is given appropriately. ${ }^{6-9}$

Procedural sedation has become the standard of care in both inpatient and outpatient settings, however, many practices are not yet evidence-based due to a lack of well-designed studies. ${ }^{10,11}$ Many agents have been tried alone and in combination but there is no consensus on procedural sedation in children. ${ }^{10-12}$ Numerous factors need to be considered when choosing an agent including the age and weight of the child; the location, depth and extent of the burn and the length of the procedure itself. 6,7

Methoxyflurane (MF) is a volatile anaesthetic agent. Historically it was used as an inhalational agent for general anaesthesia but was discontinued due to nephrotoxicity in a dose dependent manner, the upper limit of safety now suggested as 2 Minimum Alveolar Concentration (MAC)-hours. ${ }^{13-15}$ Despite this, MF is known for its analgesic properties in smaller doses and has been used as an analgesic agent, without causing nephrotoxicity or hepatotoxicity. The use of MF delivery by a hand-held inhaler is licensed for both adults and children in Australia, resulting in the majority of studies on its use from this setting. ${ }^{13-16}$ Safety and efficacy of low dose inhaled MF have been demonstrated for analgesia and sedation. ${ }^{15}$ Previous literature has described the use of MF in the prehospital emergency setting ${ }^{16}$ and for minor surgical procedures. ${ }^{13}$

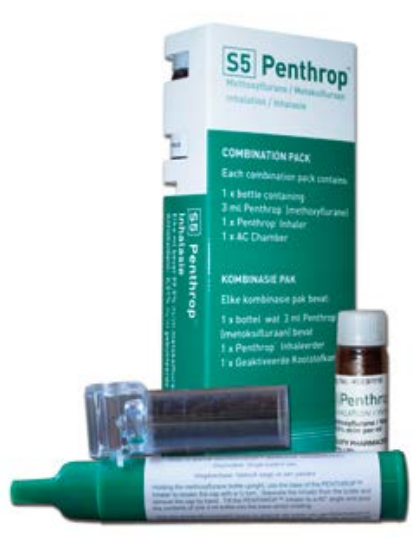

Figure 1: Penthrop ${ }^{\circledR}$ inhaler
Within the South African context MF is also currently registered as a Penthrop ${ }^{\circledR}$ inhaler (Figure 1). It is a portable, hand-held inhaler, requiring patient effort and cooperation. The inhaler delivers a concentration of $0.2 \%$ (MAC of methoxyflurane is $0.16 \%$ ) and comprises an activated carbon filter, a diluter hole (which when occluded, can increase the concentration) and a 
$3 \mathrm{ml}$ vial of MF which is poured onto a wick. ${ }^{13} \mathrm{MF}$ has a high lipid solubility, but despite this onset of action (when using the agent for sedation and analgesia) is within 6-10 breaths. ${ }^{13}$ Duration of action is reported from 30 minutes to one hour depending on continuous versus intermittent use. ${ }^{13}$ Three (3) $\mathrm{ml}$ of MF is under the safety limit in that it provides 0.3 MAC-hours. ${ }^{15} \mathrm{~A}$ second dose is still within the safety limit with 0.59 MAC-hours. ${ }^{17}$ Indications include acute pain relief, anxiolysis and sedation, or alternatively procedural analgesia for small surgical procedures. Contraindications include renal or hepatic impairment; cardiovascular, respiratory, or neurological compromise; history of malignant hyperthermia, porphyria or hypersensitivity to inhalational anaesthetic agents. ${ }^{18}$

There is a significant burden of disease with regards to burns in children in our resource constrained setting. The Paediatric Burns Unit at Chris Hani Baragwanath Academic Hospital (CHBAH) is the only dedicated paediatric burns unit in Gauteng in the largest hospital on the African continent. Approximately 450 children are admitted to the unit per annum. The unit has 21 ward beds and 7 intensive care unit (ICU) beds. If the ward is at capacity, 14 children undergo burns dressing changes a day, with no available doctor present to administer sedation and analgesia in a monitored and safe environment. Current practice involves the use of ketamine as a single agent in doses ranging from 1-5 mg/kg (IVI/IMI), administered and monitored by the nursing staff. This highlights the need for an efficacious and safe agent in this setting.

\section{Methods}

\section{Study design and setting}

A prospective nonrandomised, nonblinded observational descriptive case series was conducted in the paediatric burn ward of $\mathrm{CHBAH}$.

Children between the ages of 4-10 years who were undergoing dressing changes for their burn wounds were deemed eligible. At least one of the investigators was present for the procedure, prescribed the MF, supervised administration thereof and monitored the patient throughout the procedure.

Patients were excluded if they were admitted to the ICU, had known risk for malignant hyperthermia, had existing renal or hepatic impairment or known additional risk factors for renal or hepatic impairment. Contraindications to MF use including hypersensitivity to fluorinated anaesthetics, cardiovascular instability, respiratory depression, depressed level of consciousness, family history of adverse reaction to volatile anaesthetics or porphyria were also used as exclusion criteria. Patients who had not followed correct starvation guidelines were also excluded.

Over a six-month period, participants were identified in the ward after admission. Informed parental consent as well as informed patient assent was obtained. Once consent was granted the patient was educated on correct device use.
The MF inhaler was primed with $3 \mathrm{ml}$ of MF to supply $0.1-0.2 \%$, according to the supplier's guidelines. ${ }^{18}$ During the procedure MF was self-administered by inhalation through a hand-held whistle shaped Penthrop ${ }^{\oplus}$ inhaler, if children struggled with the whistle, a face mask was placed over the "whistle end" to ease administration and improve the seal. The activated carbon filter was connected to the device for every procedure. If inadequate analgesia was noted, the bypass hole could be occluded to increase the dose of MF delivered. If this was insufficient, the protocol would be to stop the dressing change and revert to the unit's standard of care or the procedural analgesia. In South Africa, the minimum effective dose to produce analgesia as recommended in the package insert, is $3 \mathrm{ml}$ per day or $15 \mathrm{ml}$ per week in children 1-11 years of age. ${ }^{18}$ All patients only had one exposure to MF during their admission ensuring they were well below the maximum dose.

Information collected pre-procedure included weight and gender of the child, date of admission and date of procedure, percentage burn of total body surface area (TBSA), location of the burn and aetiology of the burn, as well as depth of the burn. During the procedure, the following were recorded: duration of MF exposure, vital signs including heart rate, oxygen saturation, blood pressure and respiratory rate at baseline then at 2 minutes and 5 minutes and every 5 minutes thereafter until procedure completion. Depth of sedation was recorded by the investigators using the Wisconsin Sedation Scale (WSS) ${ }^{19}$ shown in Table I. The FLACC (face, legs, activity, cry, consolability) score ${ }^{20}$ (Table II) was used to assess pain. Pain and sedation scales were recorded at the same intervals as vital signs were recorded. Post-procedure, level of staff satisfaction with the procedure was detailed using a Likert scale (very dissatisfied/dissatisfied/neutral/satisfied/very satisfied). The sister performing the procedure was also asked to comment on her experience during the dressing change.

Adverse events were predefined as desaturation $<92 \%$, airway complications, apnoea, aspiration, cardiovascular instability, nausea and vomiting, permanent neurological injury and death. Staff who were pregnant or known with renal or hepatic impairment were not involved in data collection to ensure occupational health and safety.

Data were captured and analysed using Microsoft Excel ${ }^{\circledR} 2016$. Descriptive and inferential statistics were used, and categorical variables were described using frequencies and percentages. Data is reported using means and medians with interquartile ranges.

\section{Results}

Twelve patients were enrolled for the study with an age range of 4-9 years. The percentage of TBSA affected by the burns ranged from $3-13 \%$. All but two of the patients sustained partialthickness burns. With regards to aetiology of the burns, ten of the patients sustained hot water burns, one patient had flame burns and one patient sustained burns from other causes. 
Table I: Sedation assessment with Wisconsin Sedation Scale

\begin{tabular}{llll}
\hline Sedation classification & Sedation score & Description \\
\hline Inadequate sedation & 6 & Anxious, agitated, or in pain \\
\hline Minimal conscious sedation & 5 & Spontaneously awake without stimulus \\
\hline Moderate conscious sedation & 4 & Drowsy, eye open or closed, but easily arouses consciousness with verbal stimuli \\
\hline Moderate-deep conscious sedation & 3 & Arouses to consciousness with moderate tactile or loud verbal stimuli \\
\hline Deep sedation & 2 & Arouses slowly to consciousness with sustained painful stimulus \\
\hline Anaesthesia & 1 & Arouses, but not to consciousness, with painful stimulus \\
\hline
\end{tabular}

Table Il: Pain assessment with FLACC score

\begin{tabular}{|c|c|c|c|}
\hline Category & Scoring & & \\
\hline & 0 & 1 & 2 \\
\hline Face & $\begin{array}{l}\text { No particular expression } \\
\text { or smile }\end{array}$ & $\begin{array}{l}\text { Occasional grimace or frown, } \\
\text { withdrawn, disinterested }\end{array}$ & $\begin{array}{l}\text { Frequent to constant quivering chin, } \\
\text { clenched jaw }\end{array}$ \\
\hline Legs & Normal position or relaxed & Uneasy, restless, tense & Kicking or legs drawn up \\
\hline Activity & $\begin{array}{l}\text { Lying quietly, normal position, } \\
\text { moves easily }\end{array}$ & $\begin{array}{c}\text { Squirming, shifting back and forth, } \\
\text { tense }\end{array}$ & Arched, rigid or jerking \\
\hline Cry & No cry (awake or asleep) & $\begin{array}{l}\text { Moans or whimpers, } \\
\text { occasional complaint }\end{array}$ & $\begin{array}{l}\text { Crying steadily, screams or sobs, } \\
\text { frequent complaints }\end{array}$ \\
\hline Consolability & Content, relaxed & $\begin{array}{c}\text { Reassured by occasional touching, } \\
\text { hugging, or being talked to, distractible }\end{array}$ & Difficult to console or comfort \\
\hline
\end{tabular}

Table III: Procedure information with pain and sedation scores

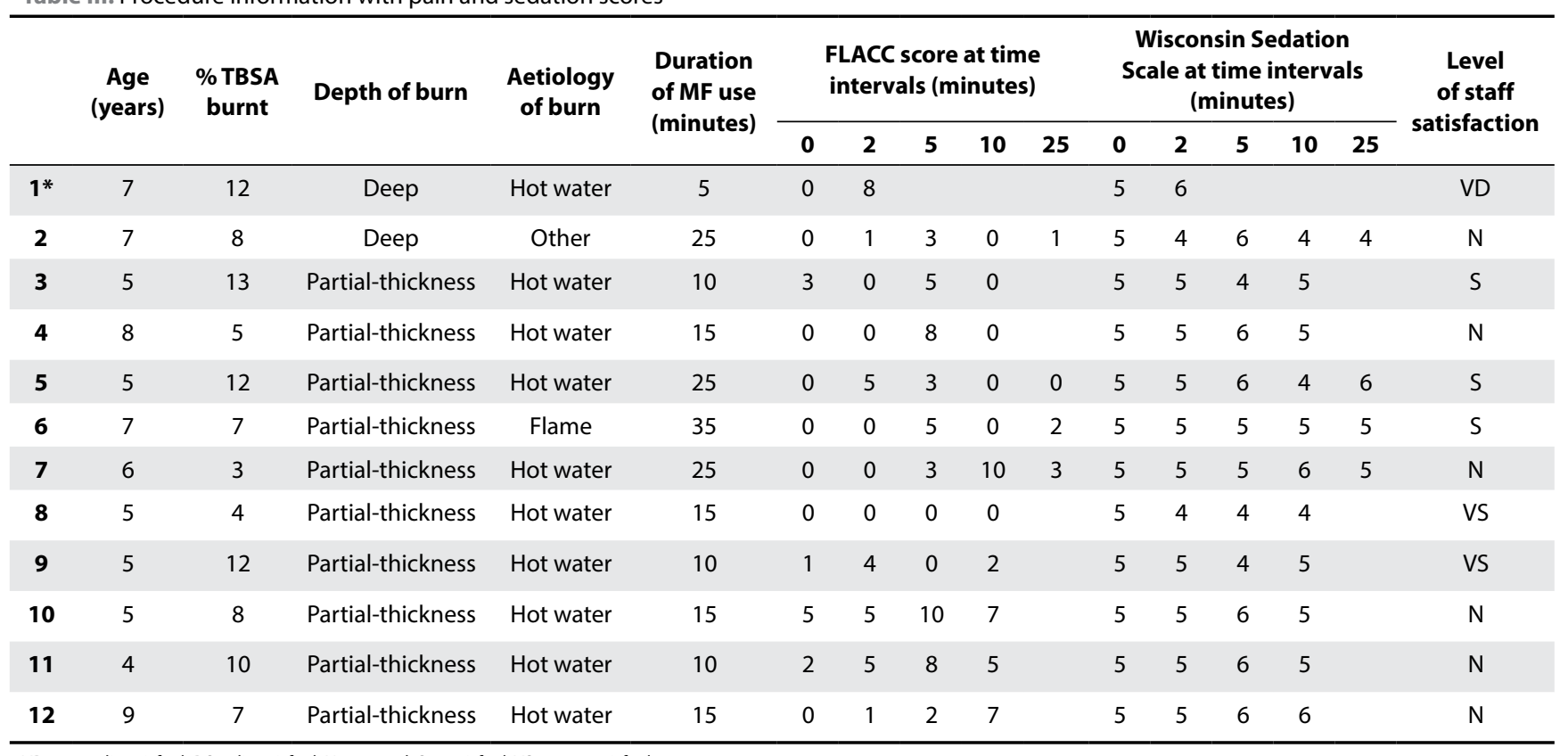

VD - very dissatisfied, DS - dissatisfied, $\mathrm{N}$ - neutral, S - satisfied, VS - very satisfied *procedure abandoned due to insufficient analgesia

Methoxyflurane was used as the sole agent for analgesia and sedation for the entire duration of the procedure. One dressing change was abandoned and the treatment defaulted to current standard of care, as the patient had insufficient analgesia using MF. The median time of each dressing change was 15 min (IQR:10-25) (excluding the abandoned procedure). The procedure had three components: removing old dressings, scrubbing the wounds, and then replacing with new dressings.

No major adverse events (as defined by our study) were noted. There were no episodes of desaturation noted and none of the patients required any form of airway or haemodynamic support during the procedure. Mild adverse events included euphoria and delirium. Staff reported noting the strong smell of MF while procedures occurred.

Table III illustrates FLACC score and WSS during the procedure for each patient at various time intervals. Investigators noted that during the initial exposure and replacement of the burn wound dressings, analgesia and sedation levels were sufficient and appropriate respectively for the majority of the patients. However, with regards to analgesia, using MF during the 
scrubbing of the wounds proved insufficient in $36.4 \%$ of the patients. In addition, $63.6 \%$ of patients demonstrated anxiety during the scrubbing of wounds. It should be noted that the first case of the study was abandoned, and the dressing change was postponed to be done using the standard protocol in the unit. It was noted that this patient had undergone traumatic burn injuries with multiple previous dressing changes with insufficient analgesia and sedation. The decision to continue with the study was made in discussion with experts in paediatric anaesthesia, doctors and nursing staff working in the unit.

In assessing staff satisfaction with regards to MF use: in six of the cases the staff expressed neutral feelings towards using the drug, in three of the cases, staff were satisfied and in two of the cases they were very satisfied. Note, in the procedure that was abandoned, the staff demonstrated they were very dissatisfied with the MF use.

The common positive themes from comments received the end of the procedure included: good analgesia and the patients were fully conscious and able to mobilise and eat immediately after the procedure compared to children who received ketamine. Negative themes in the comments included: there was insufficient sedation and the children were delirious and restless making the dressing more difficult.

\section{Discussion}

The majority of literature found on the use of MF demonstrated mostly observational studies on a small scale. The proposed reason for this is as a result of its limited licensing on the global scale. Despite small, observational studies, the safety of MF use has been highlighted., ${ }^{913-16}$ Recent announcements regarding the introduction of MF into the UK and Europe may result in the emergence of larger scaled literature.

Specifically, within the paediatric population, there is a paucity of literature regarding the use of MF. Despite this, Babl et al. ${ }^{21}$ showed reduction in pain scores and sedation in children with the use of MF in the prehospital setting in a single centre, prospective, observational series. In addition, no major adverse events were reported. A pilot study on the successful use of MF in children for procedural analgesia was subsequently published.22 They reported positive results with no adverse events and improved pain scores in their patients. Their patient population range was a larger age group than those in our study. The majority of their procedures were orthopaedic and of a shorter duration than our study. We suggest these factors contributed to their positive findings. In our setting, patients were of a younger age group, with a mean age of six. Unfortunately, with regards to our patient population, many had been exposed to previous dressing changes themselves or witnessed other patients undergoing dressing changes. This contributed to the high anxiety levels noted in our study.

No literature on the use of MF for burns dressing changes in the paediatric population could be found. Another Australian observational study in $2012^{9}$ reported results on burn wound procedures in the adult population in the outpatient setting. These authors once again demonstrated safety with no major adverse events reported. In addition, they described reduced anxiety levels with MF use. However, they did describe, higher pain scores after the procedure with MF. Our study results mirror theirs in that we did show insufficient analgesia over two thirds of our patients during the scrubbing of burn wounds. It should be noted that within our patient population the percentage of body surface area was higher, and the depth of burn was more severe when compared to the population from Wasiak et al. ${ }^{9}$

It should also be noted that our study was conducted at moderate high altitude. One can assume that the influence of altitude on MF is similar to nitrous oxide with a reduction in partial pressure delivered at altitude. This could theoretically result in a reduction in efficacy of the agent at altitude. Analysis of this was beyond the scope of this study.

It should be reiterated that the use of MF facilitated shorter time to mobilisation and eating. As nutrition is critical for the healing of burns, and children who sustain larger burns can be hypercatabolic, this may be of benefit.

Although not measured in our study, a safety concern regarding the euphoria and delirium associated with MF use was noted. The burn dressing room contains an elevated bath to allow for the cleaning of the wounds as well as elevated tables for the provision of dressings. Due to staff limitation and the ergonomics of this area the risk of a fall is high if a patient is uncooperative.

The use of the MF inhaler provides a setting for patient-controlled analgesia and sedation. Our patient population, despite education and coaching on the use of the inhaler often failed to use it appropriately which may have contributed to inadequate dosage and effect of the drug. The use of a mask attached to the inhaler allowed for easier use (as the children could inhale through mouth and nose) and we suggest this addition when using the Penthrop ${ }^{\oplus}$ inhaler for children.

In our resource constrained environment, the authors hoped to find a safe and effective means to provide good analgesia and anxiolysis for our patient population. The results demonstrated an inadequacy with regards to the use of MF for inpatient burns dressings for the paediatric population in our setting. It should be reiterated that our dressing changes are conducted by a single member of nursing staff without the availability of a doctor at all times. An additional staff member would be required with the sole responsibility of assisting the child with the administration of MF.

The ideal agent would be a safe drug with no adverse effects especially with regards to the haemodynamic and respiratory systems. The Penthrop ${ }^{\circledR}$ inhaler has demonstrated this in the literature and our study. However, the authors feel we were unable to demonstrate satisfactory levels of analgesia and anxiolysis in our patients. It should be noted our study had a limited number of patients due to our age inclusion criteria and the inability to obtain consent and/or assent for other patients. 
We conducted an observational study without comparison to the current standard of care. Further recommendations could include a randomised control trial to accurately assess the use of MF compared to that of ketamine in this setting.

With the approval of the use of MF inhalers, we anticipate further studies which would help to delineate accurate guidelines regarding appropriate patient and procedure selection. A randomised, double blind, multicentre, placebo-controlled study using MF for children with acute pain presenting to the Emergency Department is currently underway in Europe (ClinicalTrialsRegister.eu number NCT03215056).

We suggest from our findings that this agent may not be suitable as a sole agent for inpatient burns dressing changes in children. However, its use may be appropriate in the ambulatory setting in both adult and paediatric patients, as well as the inpatient setting for adult burns patients. We suggest MF may also be of value when used as an adjunct to usual practice, for procedures involving the paediatric burns inpatient.

\section{Acknowledgements}

To Equity Pharmaceuticals (PTY) LTD for providing inhalers to be used for the study free of charge.

\section{Conflict of interest}

The authors declare no conflict of interest.

\section{Ethical approval}

Approval for the study was obtained from the Human Research Ethics Committee, Medical (approval number: M190114).

\section{ORCID}

MA Wellbeloved (D) https://orcid.org/0000-0002-1094-190x

R Parkhurst (iD https://orcid.org/0000-0003-2138-187x

KH Keeling (D) https://orcid.org/0000-0001-9054-8405

\section{References}

1. Hyder AA, Kashyap KS, Fishman S, Wali SA. Literature Review: Review of childhood burn injuries in sub-Saharan Africa: a forgotten public health challenge. Afr Saf Promot J Inj Violence. 2004;2(2):43-58. https://doi.org/10.4314/ asp.v2i2.31610.

2. Rayner R, Prentice J. Paediatric burns: a brief global review. Wound Pract Res J Aust Wound Manag Assoc. 2011 Mar;19(1):39-46.
3. Parbhoo A, Louw QA, Grimmer-Somers K. A profile of hospital-admitted paediatric burns patients in South Africa. BMC Res Notes. 2010 Jun 11:3(1):165. https://doi.org/10.1186/1756-0500-3-165.

4. Albertyn R, Numanoglu A, Rode H. Pediatric burn care in sub-Saharan Africa. Afr JTrauma. 2014;3(2):61-7. https://doi.org/10.4103/1597-1112.154921.

5. Nthumba PM. Burns in sub-Saharan Africa: A review. Burns. 2016 Mar;42(2):258 66. https://doi.org/10.1016/j.burns.2015.04.006

6. Fagin A, Palmieri TL. Considerations for pediatric burn sedation and analgesia. Burns Trauma. 2017 Oct 16;5:28. https://doi.org/10.1186/s41038-017-0094-8.

7. Thompson EM, Andrews DD, Christ-Libertin C. Efficacy and safety of procedural sedation and analgesia for burn wound care. J Burn Care Res Off Publ Am Burn Assoc. 2012 Aug;33(4):504-9. https://doi.org/10.1097/BCR.0b013e318236fe4f.

8. Ebach DR, Foglia RP, Jones $M B$, et al. Experience with procedural sedation in a pediatric burn center. J Pediatr Surg. 1999 Jun;34(6):955-8. https://doi org/10.1016/S0022-3468(99)90767-4.

9. Wasiak J, Mahar PD, Paul E, et al. Inhaled methoxyflurane for pain and anxiety relief during burn wound care procedures: an Australian case series. Int Wound J. 2014 Feb;11(1):74-8. https://doi.org/10.1111/j.1742-481X.2012.01067.x.

10. Baarslag MA, Allegaert K, Knibbe CAJ, Van Dijk M, Tibboel D. Pharmacological sedation management in the paediatric intensive care unit. J Pharm Pharmacol. 2017 May;69(5):498-513. https://doi.org/10.1111/jphp.12630.

11. Krauss B, Green SM. Procedural sedation and analgesia in children. Lancet. 2006 Mar 4;367(9512):766-80. https://doi.org/10.1016/S0140-6736(06)68230-5.

12. Hartling $L$, Milne $A$, Foisy $M$, et al. What works and what's safe in pediatric emergency procedural sedation: an overview of reviews. Acad Emerg Med Off J Soc Acad Emerg Med. 2016;23(5):519-30. https://doi.org/10.1111/acem.12938.

13. Jephcott C, Grummet J, Nguyen N, Spruyt O. A review of the safety and efficacy of inhaled methoxyflurane as an analgesic for outpatient procedures. $\mathrm{Br} J$ Anaesth. 2018 May;120(5):1040-8. https://doi.org/10.1016/j.bja.2018.01.011.

14. Gaskell AL, Jephcott CG, Smithells JR, Sleigh JW. Self-administered methoxyflurane for procedural analgesia: experience in a tertiary Australasian centre. Anaesthesia. 2016 Apr;71(4):417-23. https://doi.org/10.1111/anae.13377.

15. Dayan AD. Analgesic use of inhaled methoxyflurane: Evaluation of its potential nephrotoxicity. Hum Exp Toxicol. 2016 Jan;35(1):91-100. https://doi.org/10.1177 $\% 2 F 0960327115578743$.

16. Buntine $P$, Thom O, Babl F, Bailey M, Bernard S. Prehospital analgesia in adults using inhaled methoxyflurane. Emerg Med Australas EMA. 2007 Dec;19(6):50914. https://doi.org/10.1111/j.1742-6723.2007.01017.x.

17. Porter KM, Dayan AD, Dickerson S, Middleton PM. The role of inhaled methoxyflurane in acute pain management. Open Access Emerg Med OAEM 2018 Oct 18;10:149-64. https://doi.org/10.2147/OAEM.S181222.

18. Equity Pharmaceuticals (PTY) LTD. Penthrop inhaler (Package insert). Johannesburg, South Africa; 2014.

19. Hoffman GM, Nowakowski R, Troshynski TJ, Berens RJ, Weisman SJ. Risk reduction in pediatric procedural sedation by application of an American Academy of Pediatrics/American Society of Anesthesiologists process model. Pediatrics. 2002 Feb;109(2):236-43. https://doi.org/10.1542/peds.109.2.236.

20. Merkel SI, Voepel-Lewis T, Shayevitz JR, Malviya S. The FLACC: a behavioral scale for scoring postoperative pain in young children. Pediatr Nurs. 1997 Jun;23(3):293-7.

21. Babl FE, Jamison SR, Spicer $M$, Bernard $S$. Inhaled methoxyflurane as a prehospital analgesic in children. Emerg Med Australas EMA. 2006 Aug;18(4):404-10. https://doi.org/10.1111/j.1742-6723.2006.00874.x.

22. Babl F, Barnett P, Palmer G, Oakley E, Davidson A. A pilot study of inhaled methoxyflurane for procedural analgesia in children. Paediatr Anaesth. 2007 Feb;17(2):148-53. https://doi.org/10.1111/j.1460-9592.2006.02037.x. 